\title{
Seroprevalence of Brucella species among women with miscarriage in Jordan
}

M.N. Abo-Shehada and M. Abu-Halaweh ${ }^{2}$

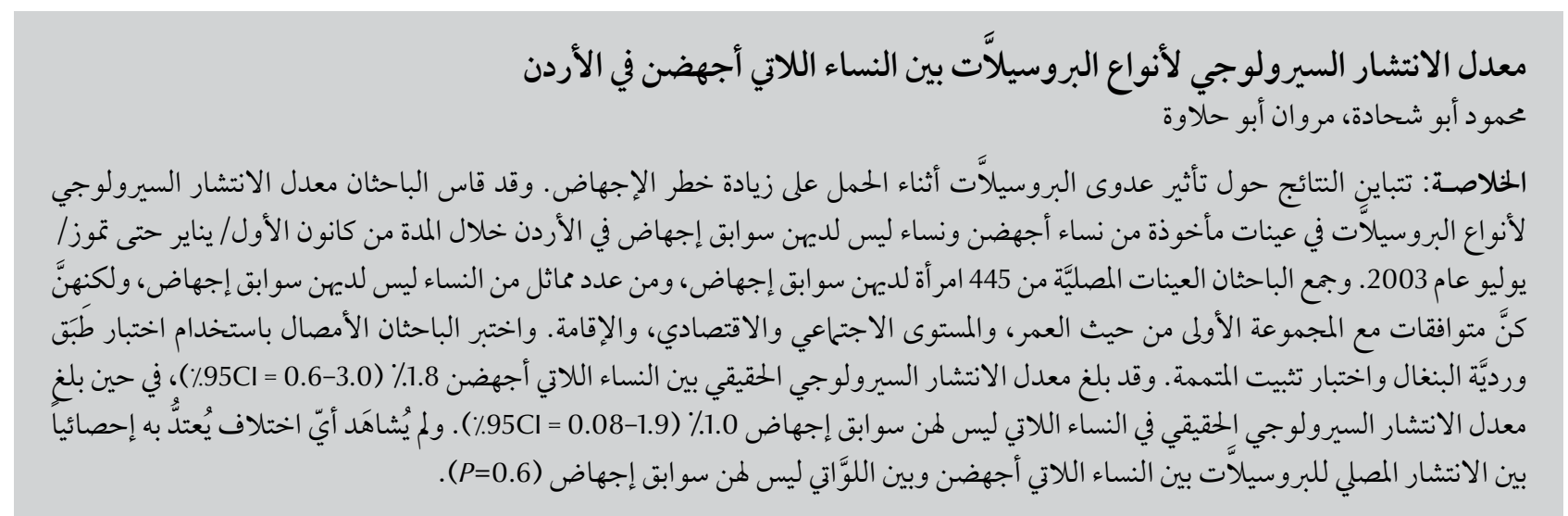

ABSTRACT Results differ as to whether Brucella infection during pregnancy increases a woman's risk of miscarriage. We determined the seroprevalence of Brucella spp. among a sample of women with miscarriage and women with no history of miscarriage in Jordan during January-July 2003. Serum samples were collected from 445 women with miscarriage and a similar number of women with no history of miscarriage, matched on age, socioeconomic status and residence. Sera were tested using the Rose Bengal plate test and complement fixation test. The true seroprevalence among women with miscarriage was $1.8 \%(95 \% \mathrm{Cl}: 0.6-3.0)$, while the true seroprevalence among women with no history of miscarriage was $1.0 \%(95 \% \mathrm{Cl}: 0.08-1.9)$. There was no significant difference between seroprevalences of Brucella spp. among women with miscarriage and those with no history of miscarriage $(P=0.6)$.

\section{Séroprévalence de l'espèce Brucella chez des femmes ayant des antécédents de fausse couche en Jordanie}

RÉSUMÉ Les résultats de la recherche sur l'augmentation du risque de fausse couche chez les femmes atteintes de brucellose pendant leur grossesse sont discordants. Nous avons déterminé la séroprévalence de Brucella spp. dans un échantillon de femmes ayant des antécédents de fausse couche et dans un groupe de femmes sans antécédent de fausse couche en Jordanie, entre janvier et juillet 2003. Des échantillons de sérum ont été prélevés auprès de 445 femmes ayant des antécédents de fausse couche. Un nombre équivalent d'échantillons a été prélevé dans un groupe de femmes sans antécédent, appariées pour l'âge, le niveau socioéconomique et le lieu de résidence. Les échantillons de sérum ont été analysés à l'aide de l'épreuve au rose Bengale et du test de fixation du complément. La séroprévalence réelle chez les femmes ayant des antécédents de fausse couche était de 1,8 \% (IC à $95 \%$ : 0,6-3,0), alors que chez les femmes sans antécédent, elle était de 1,0 \% (IC à 95 \% : 0,08-1,9). Aucune différence significative n'a été observée entre les séroprévalences de Brucella spp. chez les femmes ayant des antécédents de fausse couche et les autres $(P=0,6)$.

'Parasitology Research Laboratory, Department of Basic Veterinary Medical Sciences, Faculty of Veterinary Medicine, Jordan University of Science and Technology, Irbid, Jordan (Correspondence to M.N. Abo-Shehada:mnshehada@hotmail.com).

${ }^{2}$ Department of Biotechnology and Genetic Engineering, Faculty of Science, Philadelphia University, Amman, Jordan.

Received: 14/07/09; accepted: 04/05/10 


\section{Introduction}

Brucellosis, which is caused by organisms belonging to the genus Brucella is one of the five common bacterial zoonoses worldwide [1]. It has a global distribution, and is endemic in the Mediterranean basin, the Middle East, India, and South America [2,3]. Human brucellosis is caused by different species and includes those that cause infection in cattle (B. abortus), goats and sheep (B. meletensis), pigs (B. suis), and dogs (B. canis), with both B. melitensis and B. suis being more virulent in humans $[4,5]$.

It has been estimated that more than 500000 human Brucella spp. infections occur per year with most reported cases occurring in the Syrian Arab Republic, followed by Mongolia, Kyrgyzstan and Iraq [6]. Brucella spp. are transmitted to humans by direct contact with infected animals or their excreta or the consumption of unpasteurized milk or dairy products [7].

In animals, Brucella spp. is an established major cause of miscarriage and serious economic loss to dairy and small ruminant farms [8]. Conversely, many reports have excluded Brucella from being a cause of miscarriage in women. The reports are based on the lack of carbohydrate erythritol in women's placentas considered to be a growth factor for Brucella spp. in the placentas of animals, the presence of anti-Brucella activity in human amniotic fluid $[9,10]$, the absence of a significant relationship between Brucella antibody and spontaneous miscarriage [11], and the unsuccesfful isolation of Brucella spp. [12].

However, some of those same reports showed a significant relationship between raw milk consumption and spontaneous miscarriage [11] and a correlation between Brucella infection and preterm and intrauterine fetal death [12].

Miscarriage cases have been associated with B. abortus type $2[13]$ and $B$. melitensis [14]. It has been suggested that brucellosis can cause fetal death at any stage of pregnancy, whether maternal infection is mild or severe $[9,15]$. Associated pathological changes were preterm labour chorioamnionitis, placental abruption [13], intrauterine fetal death and Gram-negative septic shock with diffuse intravascular coagulation and septicaemia [14].

In a study in northern Jordan, the seroprevalence of Brucella was reported to be $8 \%$ among high-risk individuals (veterinarians, sheep and cattle farmers, and meat, milk and milk product handlers) compared to only $0.5 \%$ in the control sample [16], and an even higher seroprevalence of 55\% was reported among veterinarians [17]. These findings emphasize the importance of contact infection and the occupational nature of the disease in Jordan.

A better understanding of the reported association between brucellosis and miscarriage in women is needed. Few community-based studies have been carried out in Jordan and little is known about human brucellosis and miscarriage in the Middle East, including Jordan. This study therefore aimed to determine and compare the seroprevalence of Brucella spp. among Jordanian women with miscarriage and women with no history of miscarriage.

\section{Methods}

\section{Determination of sample size}

The seroprevalence of Brucella spp. was reported as $8 \%$ among high risk people in Jordan [16]. According to Thrusfield [18], the appropriate sample size was 441 , with a $99 \%$ confidence level and $1 \%$ absolute value precision.

\section{Study setting and subjects}

From January to July 2003, women with miscarriage $(n=445)$ visiting 3 main hospitals (2 public and 1 private) were surveyed for Brucella spp. The 2 public hospitals were Al-Bashir, the largest public hospital in Jordan, located in Amman, which serves patients from central Jordan especially those of poor socioeconomic standard, and Al Hussein Hospital, the fifth largest public hospital, located in the city of Salt [19]. Hiba is a private maternity hospital in Amman serving mainly patients of the Christian community. The women were recruited from the outpatient clinics of the hospitals. A qualified nurse approached them and explained the objectives of the study. Of the women approached, 48 did not want to have their blood drawn; in that case the next eligible woman was approached and recruited.

The definition of a case of miscarriage was the spontaneous end of a pregnancy after the first 6 weeks and prior to 20 weeks of gestation.

A group of 445 control women with no history of miscarriage were also recruited from women who accompanied patients to the hospitals, nurses and other hospital workers and trainees. They were actively selected and matched with the women with miscarriage for age, socioeconomic status and residence (the same village of the case). There were 121 refusals and the next woman who matched was approached and recruited.

\section{Serology}

Blood samples were collected from all the women; for the study group, the sample was taken 7-10 days after miscarriage.

Sera were separated and stored at $-20^{\circ} \mathrm{C}$ until testing. Serum samples were tested for Brucella spp. using the Rose Bengal plate test (RBPT) (JOVAC, Jordan). Positive samples were confirmed using the complement fixation test (CFT) (JOVAC, Jordan). In the case of CFT, serum samples with $17 \mathrm{IU} / \mathrm{mL}$ antibody or higher were regarded as positive. As suggested by the manufacturer, the sensitivity and specificity of RBPT are $89 \%$ and $97 \%$ respectively. CFT has a sensitivity of $88.1 \%$ and a specificity of $100 \%$ [20]. 
Positive and negative control sera were used.

\section{Data collection}

The women were interviewed using a questionnaire in Arabic which had been pilot tested. They were interviewed by a qualified nurse during the outpatient visit and at the time of blood collection. Information collected included name, age, place of residence, number of children, medication or health history.

\section{Ethical considerations}

The study protocol was approved by the concerned committees at Jordan University of Science and Technology. Verbal consent was obtained from all participants. All identifying information was kept confidential.

\section{Data analysis}

Data were analysed using SPSS, version 10.0.P $<0.05$ was considered statistically significant. The true seroprevalence and $95 \%$ confidence interval (CI) was calculated according to Rogan and Gladen [21]. The true seroprevalence is derived from the apparent seroprevalence by adjusting for the test sensitivity and specificity. The chi-squared and Fisher exact tests were used to test the significance of differences between proportions.

\section{Results}

Women with miscarriage were aged between 15 and 45 years with quartiles of, $Q 1=24$ years, $Q 2=27$ years and $\mathrm{Q} 3=32$ years. Only 9 and 7 aborted women were positive by RBPT and CFT respectively, while 5 and 4 control womenwere positive byRBPT and CFT respectively. The true seroprevalence among aborted women was 1.8\% (95\% CI: 0.6-3.0), while the true seroprevalence among women with no history of abortion was 1.0\% (95\% CI: 0.08-1.9). There was no significant difference between seroprevalence of Brucella among women with miscarriage and women with no history of miscarriage $\left(\chi^{2}=0.37\right.$, $\mathrm{df}=1, P=0.6)$. The Fisher exact test also showed no significant difference $(P=$ 0.27). Table 1 summarizes the results of positive sera.
All women with high titres were treated by the attending physician and relevant education was provided by a nurse who discussed the disease with the patients and provided a leaflet on the disease transmission.

\section{Discussion}

There was no significant difference between the true seroprevalences of women with miscarriage and women with no history of miscarriage, indicating equal exposure for both groups. However, 3 women with miscarriage had high titres of anti-Brucella antibodies (over 1:1000). The true seroprevalence among women with no history of miscarriage found in our study was similar to the reported seroprevalence of the lower risk group (0.5\%, 5 of 910$)$ [16].

As far as we know, this is the first Brucella seroprevalence study among aborted women. The same sample was tested for Toxoplasma gondii and Neospora caninum (M.N. Abo-Shehada, unpublished observations). High

\begin{tabular}{|c|c|c|c|c|}
\hline Case No. & Age (years) & $\begin{array}{c}\text { No. of } \\
\text { miscarriages }\end{array}$ & $\begin{array}{l}\text { Rose Bengal test } \\
\text { intensity }\end{array}$ & CFT titre ${ }^{a}$ \\
\hline \multicolumn{5}{|c|}{ Women with miscarriage } \\
\hline 1 & 25 & 2 & 4 & $1: 2560$ \\
\hline 2 & 37 & 1 & 1 & 0 \\
\hline 3 & 32 & 1 & 2 & $1: 160$ \\
\hline 4 & 42 & 6 & 1 & $1: 40$ \\
\hline 5 & 30 & 3 & 2 & $1: 40$ \\
\hline 6 & 34 & 2 & 1 & $1: 80$ \\
\hline 7 & 37 & 1 & 1 & 0 \\
\hline 8 & 30 & 3 & 3 & 1:1280 \\
\hline 9 & 22 & 1 & 3 & 1:1280 \\
\hline \multicolumn{5}{|c|}{ Women with no history of miscarriage } \\
\hline 1 & 35 & 0 & 3 & 1:2560 \\
\hline 2 & 28 & 0 & 2 & 1:160 \\
\hline 3 & 31 & 0 & 1 & 0 \\
\hline 4 & 32 & 0 & 4 & 1:2560 \\
\hline 5 & 26 & 0 & 2 & 1:1280 \\
\hline
\end{tabular}

${ }^{a}$ Titres $=0$ were under the cut-off value of $17 \mathrm{IU} / \mathrm{mL}$ and hence negative. Titres $\geq 1: 10$ were above the cut-off value and hence positive. CFT = complement fixation test. 
seroprevalences of both $T$. gondii and $N$. caninum were found, but none of the Brucella-seropositvesampleswerefound positive for T. gondii, and N. caninum.

Because of the low prevalence of brucellosis in both groups of women and hence the low number of seropositive women (cases) we were not able to conduct risk analysis (case-control study).

We did not examine other causes of miscarriage such as malaria, typhoid fever, syphilis and antiphospholipidantibody syndrome. Jordan is free from malaria, and malaria cases encountered are found only in Jordanian travellers to endemic countries [19].

Even though positivity for Brucella does not appear to increase the risk of miscarriage in women, in northern Jordan, more than half of the sheep and goat flocks are seropositive for $B$. melitensis [22,23], and this represents a major source of infection to humans directly through contact and indirectly through contact and consumption of animal products [1]. B. melitensis is the only species isolated in Jordan [24] and infects humans causing severe disease.

We conclude that Brucella seropositivity among Jordanian women with miscarriage and women with no history of miscarriage was similar.

\section{Acknowledgement}

This work received financial support from the Deanship of Research, University of Science and Technology, Irbid, Jordan.

\section{References}

1. Corbel MJ. Brucellosis: an overview. Emerging Infectious Diseases, 1997, 3:213-221.

2. Corbel MJ. Recent advances in brucellosis. Journal of Medical Microbiology, 1997, 46:101-103.

3. Young EJ. Brucellosis. In: Connor DH, Chandler FW, Manz HJEA, eds. Pathology of infectious diseases. Stanford, Connecticut, Appleton \& Lange, 1997.

4. Sauret JM, Vilissova N. Human brucellosis. Journal of the American Board of Family Practice, 2002, 15:401-406.

5. Young E. An overreview of human brucellosis. Clinical Infectious Diseases, 1995, 21:283-290.

6. Pappas G et al. The new global map of human brucellosis. Lancet Infectious Diseases, 2006, 6:91-99.

7. Radostits OM, Blood DC, Gay CC. Veterinary medicine. London, Bailliere Tindall, 1994.

8. Hackmon R et al. Brucellosis in pregnancy. Harefuah, 1998, 135:3-7, 88.

9. Khan MY, Mah MW, Memish ZA. Brucellosis in pregnant women. Clinical Infectious Diseases, 2001, 32:1172-1177.

10. Nassaji $\mathrm{M}$ et al. The role of Brucella infection among women with spontaneous abortion in an endemic region. Journal of the Turkish-German Gynecological Association, 2008, 9:20-23.

11. Makhseed $\mathrm{M}$ et al. Obstetric and gynecologic implication of brucellosis in Kuwait. Journal of Perinatology, 1998, 18:196199.

12. Poole PM, Whitehouse DB, Gilchrist MM. A case of abortion consequent upon infection with Brucella abortus biotype 2 . Journal of Clinical Pathology, 1972, 25:882-884.

13. Schreyer P et al. Brucella septicemia in pregnancy. European Journal of Obstetrics, Gynecology, and Reproductive Biology, 1980, 10:99-107.
14. Gholami K. Brucellosis in pregnant women. Shiraz E-Medical Journal, 2003:4(1).

15. Malone FD et al. Poor perinatal outcome associated with maternal Brucella abortus infection. Obstetrics and Gynecology, 1997, 90:674-676.

16. Abo-Shehada MN et al. Seroprevalence of brucellosis among high risk people in northern Jordan. International Journal of Epidemiology, 1996, 25:450-454.

17. Abo-Shehada MN, Rabi AZ, Abuharfeil N. The prevalence of brucellosis among veterinarians in Jordan. Annals of Saudi Medicine, 1991, 11:356-357.

18. Thrusfield M. Veterinary epidemiology. London, Blackwell Science, 1995.

19. Annual Report. Amman, Jordan, Ministry of Health, 2002.

20. Blasco JM. A review of the use of $B$. melitensis Rev 1 vaccine in adult sheep and goats. Preventive Veterinary Medicine, 1997, 31:275-283.

21. Rogan WJ, Gladen B. Estimating prevalence from the results of a screening test. American Journal of Epidemiology, 1978, 107:71-76.

22. Al-Talafhah AH, Lafi SQ, Al-Tarazi Y. Epidemiology of ovine brucellosis in Awassi sheep in Northern Jordan. Preventive Veterinary Medicine, 2003, 60:297-306.

23. Al-Malaji A. Seroepidemiology of caprine brucellosis in Jordan. Small Ruminant Research, 2005, 58:13-18.

24. Refai M. Incidence and control of brucellosis in the Near East region. Veterinary Microbiology, 2002, 90:81-110. 